\title{
Predicting kidney disease progression in patients with acute kidney injury after cardiac surgery
}

\author{
K. Annette Mizuguchi, MD, PhD, MMSc, ${ }^{\text {a }}$ Chuan-Chin Huang, ScD, ${ }^{a}$ Ian Shempp, MS, ${ }^{a}$ Justin Wang, BS, ${ }^{a}$ \\ Prem Shekar, MD, ${ }^{\mathrm{b}}$ and Gyorgy Frendl, $\mathrm{MD}, \mathrm{PhD}^{\mathrm{b}, \mathrm{c}}$
}

\section{ABSTRACT}

Objective: The study objective was to identify patients who are likely to develop progressive kidney dysfunction (acute kidney disease) before their hospital discharge after cardiac surgery, allowing targeted monitoring of kidney function in this at-risk group with periodic serum creatinine measurements.

Methods: Risks of progression to acute kidney disease (a state in between acute kidney injury and chronic kidney disease) were modeled from acute kidney injury stages (Kidney Disease: Improving Global Outcomes) in patients undergoing cardiac surgery. A modified Poisson regression with robust error variance was used to evaluate the association between acute kidney injury stages and the development of acute kidney disease (defined as doubling of creatinine 2-4 weeks after surgery) in this observational study.

Results: Acute kidney disease occurred in $4.4 \%$ of patients with no preexisting kidney disease and $4.8 \%$ of patients with preexisting chronic kidney disease. Acute kidney injury predicted development of acute kidney disease in a graded manner in which higher stages of acute kidney injury predicted higher relative risk of progressive kidney disease (area under the receiver operator characteristic curve $=0.82$ ). This correlation persisted regardless of baseline kidney function $(P<.001)$. Of note, development of acute kidney disease was associated with higher mortality and need for renal replacement therapy.

Conclusions: The degree of acute kidney injury can identify patients who will have a higher risk of progression to acute kidney disease. These patients may benefit from close follow-up of renal function because they are at risk of progressing to chronic kidney disease or end-stage renal disease. (J Thorac Cardiovasc Surg 2018;155:2455-63)

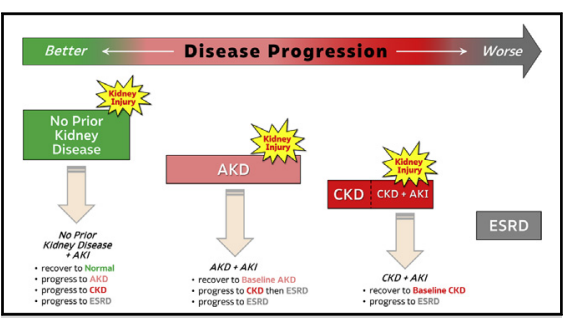

After AKI, patients may progress to AKD and then to CKD or end-stage renal disease.

\section{Central Message}

AKI definitions can be used to predict $\mathrm{AKD}$, a disease state between $\mathrm{AKI}$ and CKD in patients undergoing cardiac surgery

\section{Perspective}

Patients with AKI may sustain further worsening of kidney function that is subchronic (AKD), and some of these patients may progress to CKD. There is no reliable method to predict who with AKI is at risk for developing progressive kidney disease. This study presents a serum creatinine-based predictive model for such at-risk patients.

See Editorial Commentary page 2464
Acute kidney injury (AKI) is a common disorder associated with increased morbidity and mortality. ${ }^{1-4}$ In cardiac surgery, AKI complicates up to $30 \%$ of operations, and $1 \%$ to $2 \%$ of patients may require postoperative renal replacement therapy (RRT). ${ }^{2,4}$ Although AKI may be reversible, some patients develop subclinical or sub-acute

\footnotetext{
From the ${ }^{a}$ Division of Perioperative and Pain Medicine, Department of Anesthesiology, ${ }^{\mathrm{b}}$ Division of Cardiac Surgery, and ${ }^{\mathrm{c}}$ Surgical Critical Care Translational Research Center, Brigham and Women's Hospital, Harvard Medical School, Boston, Mass.

Received for publication March 21, 2017; revisions received Dec 15, 2017; accepted for publication Jan 2, 2018; available ahead of print March 13, 2018.

Address for reprints: K. Annette Mizuguchi, MD, PhD, MMSc, Division of Perioperative and Pain Medicine, Department of Anesthesiology, Brigham and Women's Hospital, Harvard Medical School, 75 Francis St, Boston, MA 02115 (E-mail: amizuguchi@gmail.com).

$0022-5223 / \$ 36.00$

Copyright (c) 2018 by The American Association for Thoracic Surgery

https://doi.org/10.1016/j.jtcvs.2018.01.093
}

kidney disease (AKD) that can lead to progressive kidney disease (Figure 1 and Video 1).

Kidney Disease: Improving Global Outcomes (KDIGO) AKI guidelines termed this subchronic kidney injury as "AKD and disorders." They defined AKD as kidney damage for less than 3 months after AKI, glomerular filtration rate (GFR) less than $60 \mathrm{~mL} / \mathrm{min} / 1.73 \mathrm{~m}^{2}$ for less than 3 months, or a decrease in glomerular filtration rate $35 \%$ or more or increase in $\mathrm{sCr}$ by more than $50 \%$ for less than 3 months $^{5}$ (Figure 1 and Table E1).

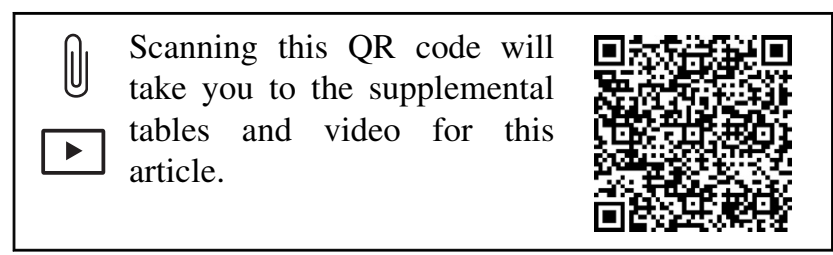




$$
\begin{aligned}
& \text { Abbreviations and Acronyms } \\
& \mathrm{AKD}=\text { acute kidney disease } \\
& \text { AKI = acute kidney injury } \\
& \mathrm{AUC}_{\mathrm{ROC}}=\text { area under the receiver operator } \\
& \text { characteristic curve } \\
& \text { CABG = coronary artery bypass grafting } \\
& \mathrm{CKD}=\text { chronic kidney disease } \\
& \text { eGFR = estimated glomerular filtration rate } \\
& \text { KDIGO }=\text { Kidney Disease: Improving Global } \\
& \text { Outcomes } \\
& \text { NKD }=\text { no known kidney disease } \\
& \text { RRT = renal replacement therapy } \\
& \mathrm{sCr}=\text { serum creatinine }
\end{aligned}
$$

Although serum creatinine $(\mathrm{sCr})$ is not an ideal biomarker for diagnosing AKI, it is an established marker of chronic kidney disease (CKD), a disease that can be clinically silent and asymptomatic until later stages. Unfortunately, current clinical practice does not require periodic $\mathrm{sCr}$ measurements in all postoperative patients after discharge because it is neither clinically indicated nor fiscally prudent. Therefore, our main objective was to determine whether early postoperative changes in $\mathrm{sCr}$ (AKI) during the index hospital admission after cardiac surgery could identify a subset of at-risk patients who will progress to $\mathrm{CKD}$ or end-stage renal disease via AKD. Identification of such patients before they are discharged from the hospital after cardiac surgery will enable targeted periodic sCr measurements in this at-risk patient group.

We hypothesized that sCr-based AKI stages can predict clinically significant decline in kidney function (development of $\mathrm{AKD}$ ), defined as doubling of $\mathrm{sCr}$ from baseline by 2 to 4 weeks after surgery in patients with no kidney disease and patients with preexisting CKD. Doubling of $\mathrm{sCr}$ was used as our outcome because it represents a significant $(\geq 50 \%)$ decrease in kidney function and is part of the KDIGO AKD definition. Our primary objective was to investigate whether the degree of AKI (AKI stages) can predict the development of AKD. Our secondary objective was to investigate whether patients who developed AKD had higher mortality and need for RRT after surgery.

\section{MATERIALS AND METHODS \\ Data Sources, Data Collection, and Patient Characteristics}

All patients who underwent cardiopulmonary bypass at Brigham and Women's Hospital from 2006 to 2014 were enrolled in the study. The data for this retrospective study were extracted from our electronic patient medical records using the RPDR query system (Partners Research, Boston, Mass). The authors' institutional review board approved this study, and the need for patient consent was waived.

Patients were divided into 2 groups: those with preoperative normal kidney function (estimated glomerular filtration rate $[\mathrm{eGFR}] \geq 60 \mathrm{~mL} / \mathrm{min}$ / $\left.1.73 \mathrm{~m}^{2}\right)$ and those with preexisting CKD $\left(\mathrm{eGFR}<60 \mathrm{~mL} / \mathrm{min} / 1.73 \mathrm{~m}^{2}\right)$. Preoperative eGFR was estimated by the isotope dilution mass spectrometry traceable Modification of Diet in Renal Disease study equation. ${ }^{6}$ Baseline sCr was defined as the closest sCr before surgery within 2 weeks of the operation.

\section{Outcomes of Interest}

The primary outcome of interest was development of postoperative AKD. AKD, a subchronic kidney injury state, was defined as doubling of $\mathrm{sCr}$ using the peak $\mathrm{sCr}$ value during the 2- to 4 -week postoperative period relative to preoperative baseline. We did not include AKI as part of the definition of AKD or urine output (Table E1). The highest $\mathrm{sCr}$ value available during this specific time period was used rather than the mean because we valued sensitivity at the expense of including false-negatives. Doubling of $\mathrm{sCr}$ was used because it met the functional criteria for AKD in the AKI guidelines and represents significant $50 \%$ or potentially $>50 \%$ ) loss of renal function. ${ }^{5}$ Mortality and need for RRT were secondary outcomes. Alternately, we also defined AKD as a decrease in eGFR $35 \%$ or more at the 2- to 4-week postoperative period. This definition was included as part of the functional criteria for AKD in the guidelines. Data using the eGFR criteria are presented in Tables E2 to E4.

According to the guidelines, AKD is defined as kidney injury less than 3 months. ${ }^{5}$ We chose this 2 - to 4 -week time after the surgery because we wanted to predict the development of sustained kidney injury closer to the acute period (ie, possibly during a reversible period) than a more chronic time point (ie, possibly irreversible period). We considered this 2- to 4 week postoperative period a point in time that reflects a period beyond the acute injury phase but before the chronic disease state, thus subchronic. We also chose this specific time because we previously found that early changes in $\mathrm{sCr}$ predicted progression of AKI to sustained kidney disease occurring 2 to 4 weeks after surgery in patients undergoing mesothelioma surgery. ${ }^{7}$

\section{Statistical Analysis}

Continuous baseline characteristics of patients with no known kidney disease (NKD) and with preexisting CKD were summarized as mean \pm standard deviation and compared using Student $t$ tests. Categoric variables were reported as absolute numbers (percentage) and analyzed using Fisher exact tests.

After univariate analyses, a multivariate prediction model including age, gender, and surgical type was generated rather than a propensity score-matching model to maintain the generalizability of the prediction model. Surgery type was categorized as the following: coronary artery bypass grafting (CABG); $\mathrm{CABG}$ and aortic or mitral valve surgery; valve surgery (without $\mathrm{CABG}$ ); heart failure surgery (heart transplantation and mechanical assist device); and other (mainly congenital and surgery on the aorta). Other covariates known to be associated with increased risk of renal injury in patients undergoing cardiac surgery, as reoperations, emergency surgery, need for intra-aortic balloon pump, history of diabetes, and hypertension, did not show significance with univariate analysis and were not included in the multivariate prediction model.

A modified Poisson regression with robust error variance was used to estimate the cumulative relative risk of the association between the stages of KDIGO AKI and the development of AKD. ${ }^{8}$ The modified Poisson regression was used because it allowed us to obtain cumulative risk ratios directly. Receiver operator characteristic curves were generated to examine the ability of the multivariate regression model using KDIGO AKI definitions to predict the development of AKD.

To evaluate the trend of AKI rates during the study period (20062014), patients with no AKI were compared with patients with AKI stage 1 and stages 2 and 3 combined. Linear regression was used to test for linear trend in AKI rates. All statistical analyses were performed using $\mathrm{R}$ software version 3.1.2 (R Foundation for Statistical Computing, Vienna, Austria). 


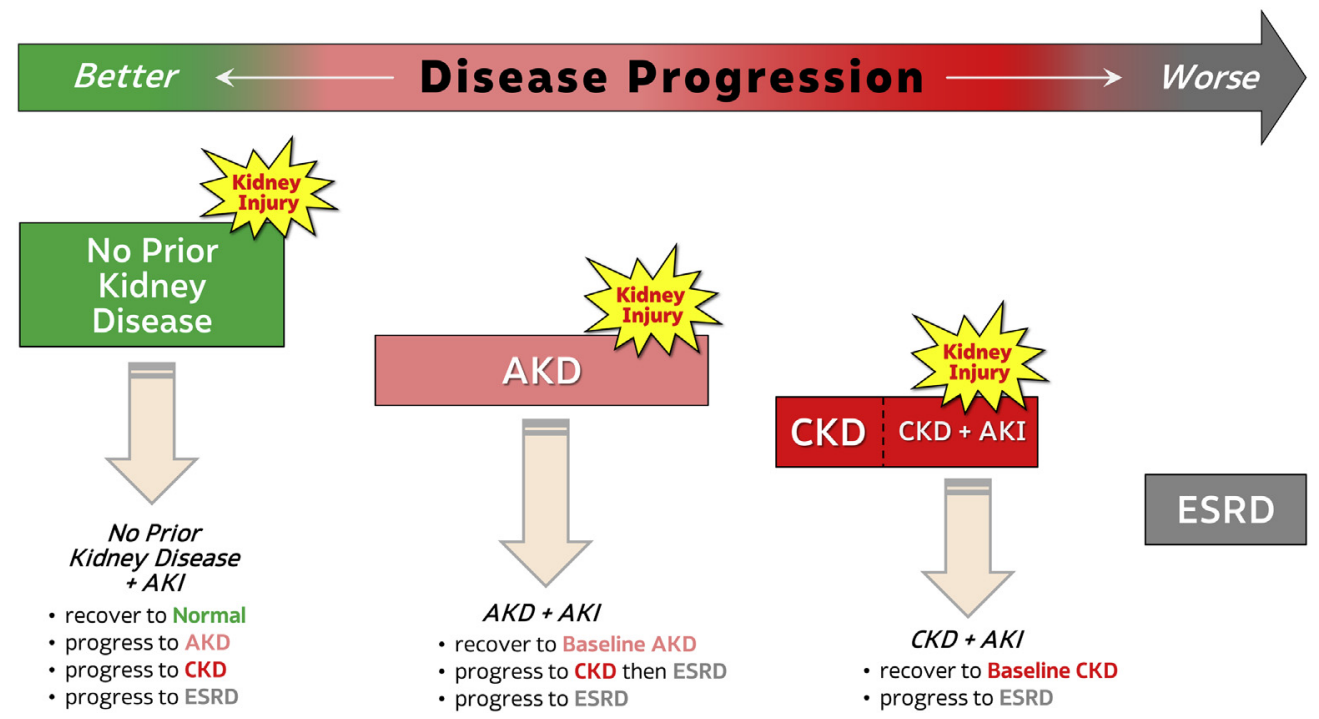

FIGURE 1. Phases of kidney disease progression from normal kidney function through AKI, AKD, and CKD to end-stage renal disease. After the initial episode of AKI, patients with NKD at baseline may (1) recover or progress to AKD, (2) progress to CKD, or (3) progress to ESRD. Patients who developed AKD may (1) progress to CKD or ESRD after other AKI events or (2) recover to baseline AKD. Likewise, patients with CKD who are exposed to AKI may (1) recover to their baseline CKD or (2) progress further to ESRD. AKI, Acute kidney injury; $A K D$, acute kidney disease; $C K D$, chronic kidney disease; ESRD, end-stage renal disease.

\section{RESULTS}

From 2006 to 2014, 10,491 patients underwent cardiac surgery under cardiopulmonary bypass at Brigham and Women's Hospital. After excluding patients aged less than 18 years $(\mathrm{n}=10)$, patients with preexisting RRT or history of kidney transplantation $(\mathrm{n}=133)$, and those who died within 2 days of surgery $(\mathrm{n}=114)$, we

\section{Predicting Kidney Disease Progression in Patients with Acute Kidney Injury after Cardiac Surgery}

K. Annette Mizuguchi, M.D., Ph.D., M.M.Sc., F.A.S.E. ${ }^{\mathrm{a}}$

Chuan-Chin Huang, Sc.D. ${ }^{\mathrm{b}}$

Ian Shempp, M.S., ${ }^{b}$

Justin Wang, B.S. ${ }^{\mathrm{b}}$

Prem Shekar, M.D.

Gyorgy Frendl, M.D., Ph.D., d,

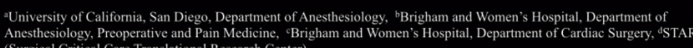

VIDEO 1. This narrated video discusses the significance of AKI in cardiac surgery and the definitions of AKI, AKD, and CKD. This video also discusses the importance of predicting the progression of AKI to CKD before kidney injury is irreversible. Video available at: http://www.jtcvsonline. org/article/S0022-5223(18)30399-4/fulltext. enrolled 10,234 patients in our observational study (Figure 2).

In our cohort of 10,234 patients, $68 \%(n=6952)$ had NKD and $32 \%(n=3282)$ had preexisting CKD. We found that $20.5 \%(\mathrm{n}=2095)$ had $\mathrm{sCr}$ values between 2 and 4 weeks. This included 1194 patients with NKD and 901 patients with preexisting kidney disease. When we compared patients with 2- to 4-week $\mathrm{sCr}$ values $(\mathrm{n}=2095)$ with those missing their 2- to 4-week $\mathrm{sCr}$ data $(\mathrm{n}=8139)$, we found that patients missing their data were healthier, as noted by their significantly lower mortality, lower need for RRT, and lower AKI rates (Table E5). For all of the studies except for the evaluation of AKI rates over the time (2006-2014), we analyzed the data for patients who had $\mathrm{sCr}$ measured during the 2- to 4-week period after surgery $(n=2095)$ as opposed to using their last $\mathrm{sCr}$ available after hospital discharge as a surrogate for their 2- to 4-week postoperative sCr values (Tables E6 and E7).

Baseline characteristics revealed that patients with preexisting CKD were older by 9 years ( 71 vs $64 ; P<.001)$, and there were more women (absolute numbers) in that group $(40.7 \%$ vs $34.5 \% ; P=.004)$ than those with $\mathrm{NKD}$ (Table 1). However, when we evaluated the percentage of men and women with AKD, they were similar (Table 2). The AKI rate (stages 1-3) was lower in patients with normal preoperative kidney function $(\mathrm{n}=303 ; 25.4 \%)$ compared with patients with preexisting CKD $(\mathrm{n}=299 ; 33.2 \%)$ (Table 1). 


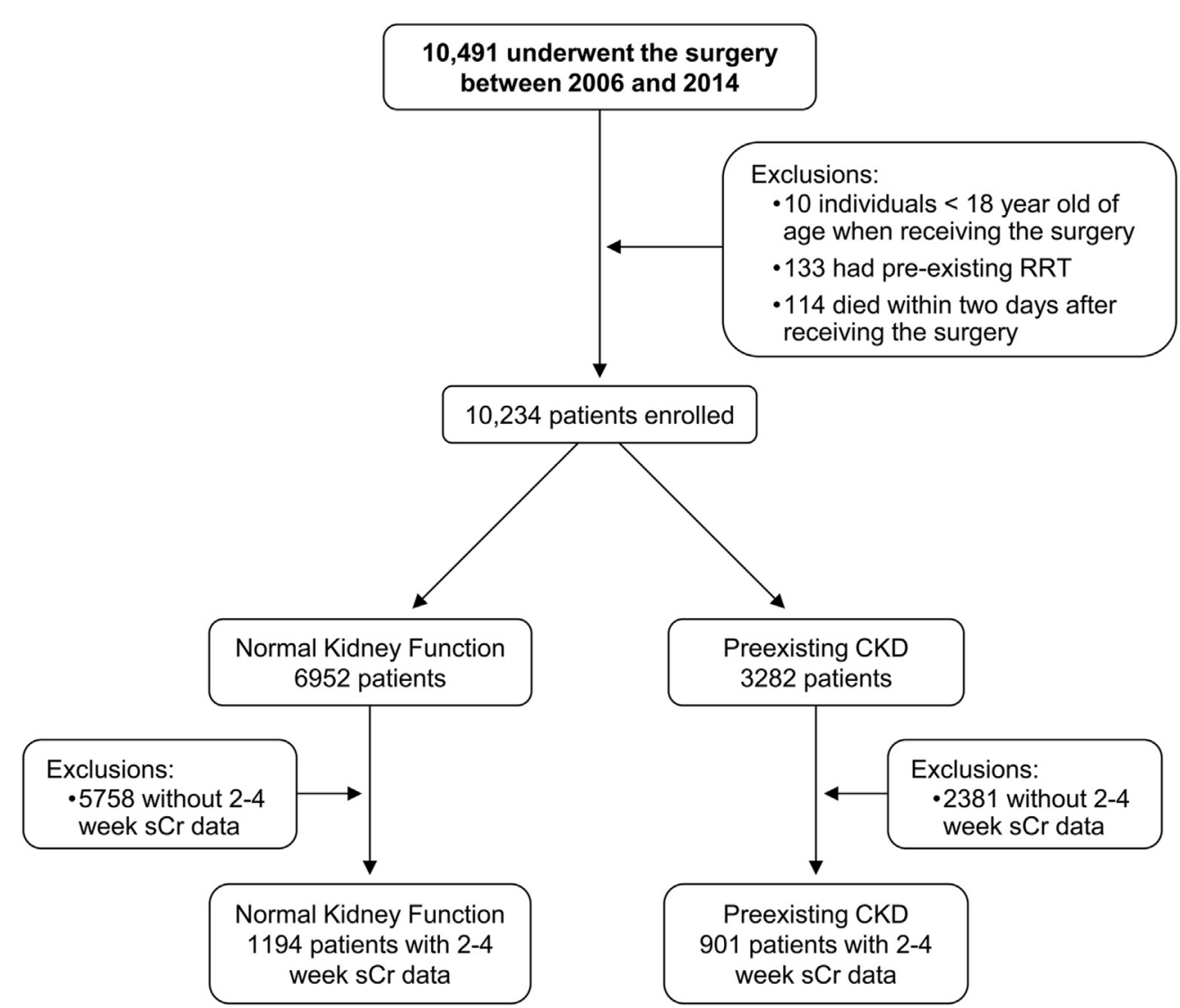

FIGURE 2. Flow diagram of study patients shows 10,234 patients were enrolled in the study after exclusions. Patients were divided into normal kidney function and preexisting CKD by glomerular filtration rate criteria. Only patients with 2- to 4-week postoperative sCr data ( $\mathrm{n}=1194$ for normal kidney function and $\mathrm{n}=901$ with preexisting $\mathrm{CKD}$ ) were included in the prediction studies. RRT, Renal replacement theory; $C K D$, chronic kidney disease; $s C r$, serum creatinine.

AKD occurred in $4.4 \%(\mathrm{n}=53)$ of patients with NKD and $4.8 \%(\mathrm{n}=43)$ of patients with preexisting CKD (Table 1). Patients who developed AKI during their hospital admission were more likely to progress to AKD than those who did not (Table 2).

\section{Effect of Acute Kidney Disease on Mortality and Need for Renal Replacement Therapy}

Patients with preexisting CKD had significantly higher in-hospital $(7.77 \%$ vs $2.35 \%)$ and 30-day mortality $(5.11 \%$ vs $1.76 \%)$ than patients with NKD (Table 1$)$. Among the patients who developed AKD with NKD, the in-hospital $(15.1 \%$ vs $1.75 \% ; P<.001)$ and 30-day $(7.6 \%$ vs $1.49 \% ; P=.006)$ mortality rates were more than 4 times higher than those who did not develop AKD (Table 2). Likewise, patients with preexisting CKD who developed AKD had higher in-hospital $(44.2 \%$ vs $5.9 \%$; $P<.001)$ and 30-day mortality $(20.9 \%$ vs $4.3 \%$; $P<.001)$ than those who did not develop AKD.

Patients with preexisting CKD were more than 3 times more likely to require RRT postoperatively than patients with NKD $(6.77 \%$ vs $1.76 \% ; P<.001)$ (Table 1$)$. More patients with NKD who developed AKD required postoperative RRT than those who did not develop AKD (22.6\% vs $0.79 \% ; P<.001$ ) (Table 2). Likewise, patients with preexisting CKD who developed AKD required postoperative RRT more often than the patients who did not develop AKD $(51.2 \%$ vs $4.6 \% ; P<.001)$ (Table 2$)$.

\section{Stages of Acute Kidney Injury Predict the Development of Acute Kidney Disease in a Graded Manner}

Although the stages of AKI have distinct definitions, the guidelines state they are not explicitly graded (ie, higher stages of AKI do not necessarily predict worse outcomes). After adjusting for age, gender, and surgical type, we found that stages of AKI predicted AKD in a graded manner (area under the receiver operator characteristic curve $\left.\left[\mathrm{AUC}_{\mathrm{ROC}}\right]=0.82-0.84\right)$ (Table 3 ). Patients who developed KDIGO AKI stages 1, 2, and 3 had a 2.3, 9.4, and 22.9 times higher relative risk of developing $\mathrm{AKD}$, respectively, regardless of their baseline kidney function, compared with those patients who did not develop AKD (Table 3). 
TABLE 1. Outcomes of patients with no known prior kidney disease and patients with preexisting chronic kidney disease after cardiac surgery

\begin{tabular}{|c|c|c|c|}
\hline $\mathbf{n}=\mathbf{2 0 9 5}$ & NKD $(n=1194)$ & Preexisting CKD $(n=901)$ & $P$ value \\
\hline \multicolumn{4}{|l|}{ Preoperative characteristics } \\
\hline Age $(y)$, mean $(\mathrm{SD})$ & $64(14.9)$ & $71(12.3)$ & $<.001$ \\
\hline Gender (male), n (\%) & $782(65.5 \%)$ & $534(59.3 \%)$ & .004 \\
\hline Preoperative sCr, mean (SD) & $0.88(0.16)$ & $1.48(0.57)$ & $<.001$ \\
\hline Preoperative eGFR, mean (SD)* & $89.8(28.8)$ & $41.2(12.7)$ & $<.001$ \\
\hline Type of surgery & & & $<.001$ \\
\hline CABG only & $279(23.4 \%)$ & $171(19.0 \%)$ & \\
\hline $\mathrm{CABG}+\mathrm{AV}$ or $\mathrm{MV}$ & $137(11.5 \%)$ & $136(15.1 \%)$ & \\
\hline Valve surgery & $335(28.1 \%)$ & $244(27.1 \%)$ & \\
\hline Heart Tx or VAD & $69(5.78 \%)$ & $103(11.4 \%)$ & \\
\hline Other $\dagger$ & $374(31.3 \%)$ & $247(27.4 \%)$ & \\
\hline \multicolumn{4}{|l|}{ Outcomes } \\
\hline \multicolumn{4}{|l|}{ Incidence of $\mathrm{AKD}$} \\
\hline Doubling of sCr; 2-4 wk after surgery & $53(4.4 \%)$ & $43(4.8 \%)$ & .798 \\
\hline \multicolumn{4}{|l|}{ Other outcomes } \\
\hline In-hospital mortality & $28(2.35 \%)$ & $70(7.77 \%)$ & $<.001$ \\
\hline 30-d mortality, \% & $21(1.76 \%)$ & $46(5.11 \%)$ & $<.001$ \\
\hline Need for RRT after surgery, $\%$ & $21(1.76 \%)$ & $61(6.77 \%)$ & $<.001$ \\
\hline Incidence of KDIGO AKI stages & & & $<.001$ \\
\hline No AKI & $891(74.6 \%)$ & $602(66.8 \%)$ & \\
\hline Stage 1 & $210(17.6 \%)$ & $199(22.1 \%)$ & \\
\hline Stage 2 & $57(4.8 \%)$ & $26(2.9 \%)$ & \\
\hline Stage 3 & $36(3.0 \%)$ & $74(8.2 \%)$ & \\
\hline
\end{tabular}

$N K D$, No known kidney disease; $C K D$, chronic kidney disease; $S D$, standard deviation; $s C r$, serum creatinine; $e G F R$, estimated glomerular filtration rate; $C A B G$, coronary artery bypass grafting; $A V$, aortic valve; $M V$, mitral valve; $T x$, transplant; $V A D$, ventricular assist device; $A K D$, acute kidney disease; $R R T$, renal replacement therapy; $K D I G O$, Kidney Disease: Improving Global Outcomes; $A K I$, acute kidney injury. *eGFR was calculated using the MDRD formula. $\dagger$ Other mainly included congenital and surgery on the aorta.

This graded response persisted whether patients had NKD or preexisting $\mathrm{CKD}\left(\mathrm{AUC}_{\mathrm{ROC}}=0.84\right.$ for both $)$ (Table 3$)$.

\section{AKI Incidence Over Time}

For this segment of our study, we used the entire cohort $(\mathrm{n}=10,234)$ because all patients had $\mathrm{sCr}$ values to evaluate AKI. We found that most of the patients did not develop AKI ( $>80 \%$ with no AKI since 2006) (Figure 3). By 2014 , the percentage of patients with no AKI increased to $89 \%$. There also seemed to be a progressive decline in the number of patients who developed AKI. This trend was noted for both patients with NKD and preexisting CKD $(P<.001$ for trends of decreasing AKI stage 1 and stages $2+3$ over time). Specifically, by 2014, the percentage of patients with AKI stages 2 or 3 decreased by $50 \%$ in both cohorts compared with data from 2006.

\section{DISCUSSION}

Patients undergoing cardiac surgery are at risk for developing AKI, and although some patients recover from AKI, other patients develop subclinical or sub-AKD that places them at risk for developing progressive kidney disease. ${ }^{5}$ Although several novel biomarkers are showing promise as a better method of diagnosing AKI, sCr is still the established method of tracking disease progression. However, it is impractical and currently not clinically indicated to follow
sCr levels in all patients who undergo cardiac surgery after they are discharged. Therefore, we were interested in identifying the subset of patients who would truly benefit from periodic $\mathrm{sCr}$ measurements after discharge.

We hypothesized that the degree of AKI (AKI stages) predicts the development of AKD (defined as doubling of sCr present 2-4 weeks after surgery) in patients with NKD and preexisting CKD. We confirmed our initial hypothesis and found that the degree of AKI can be used to predict risk of subsequent development of AKD for patients with NKD and patients with preexisting CKD. We also found that KDIGO AKI stages predicted the development of AKD in a graded manner in which patients classified with higher stages of AKI had a higher risk of developing AKD (Table 3). This is likely the first report demonstrating that AKI stages can predict disease progression from AKI to $\mathrm{AKD}$ in a graded manner.

As in our clinical experience, we found that patients with preexisting CKD had worse outcomes compared with patients with normal kidney function in regard to mortality and need for RRT. Patients with preexisting CKD had a higher incidence of AKI and AKD. Therefore, this confirms prior observations that patients with preexisting CKD are at higher risk for perioperative morbidities (including progressive kidney dysfunction) than those with normal baseline kidney function. 
TABLE 2. Outcomes of patients with acute kidney disease

\begin{tabular}{|c|c|c|c|c|c|c|}
\hline \multicolumn{7}{|c|}{ Patient characteristics } \\
\hline & \multicolumn{3}{|c|}{ NKD $(n=1194)$} & \multicolumn{3}{|c|}{ Preexisting CKD $(n=901)$} \\
\hline & $\mathbf{A K D}(\mathbf{n}=\mathbf{5 3})$ & $\begin{array}{c}\text { No AKD } \\
(n=1141)\end{array}$ & $P$ value & $\operatorname{AKD}(n=43)$ & $\begin{array}{l}\text { No AKD } \\
(n=858)\end{array}$ & $P$ value \\
\hline Age $(y)$, mean $(S D)$ & $64(17.5)$ & $64(14.8)$ & .83 & $72.1(12.2)$ & $70.7(12.3)$ & .459 \\
\hline $\begin{array}{l}\text { Gender (male) } \\
\% \text { male with } \mathrm{AKD}^{*} \\
\% \text { female with } \mathrm{AKD} *\end{array}$ & $\begin{array}{r}38(71.1 \%) \\
4.9 \%(38 / 782) \\
3.6 \%(15 / 412)\end{array}$ & $744(65.2 \%)$ & .41 & $\begin{array}{r}24(55.8 \%) \\
4.5 \%(24 / 534) \\
5.2 \%(19 / 367)\end{array}$ & $510(59.4 \%)$ & .754 \\
\hline Preoperative $\mathrm{sCr}$, mean (SD) & $0.86(0.18)$ & $0.88(0.16)$ & .56 & $1.4(0.42)$ & $1.39(0.45)$ & .729 \\
\hline Preoperative eGFR, mean (SD) $\dagger$ & $96.1(35.5)$ & $89.6(28.4)$ & .2 & $42.4(11.8)$ & $43.8(11.8)$ & .34 \\
\hline \multicolumn{7}{|c|}{ Type of surgery } \\
\hline $\begin{array}{l}\text { CABG only } \\
\% \text { CABG only with } \mathrm{AKD}_{\ddagger}^{\ddagger}\end{array}$ & $\begin{array}{l}11(20.75 \%) \\
3.9 \%(11 / 279)\end{array}$ & $268(23.5 \%)$ & .011 & $\begin{array}{c}6(14.0) \\
3.5 \%(6 / 172)\end{array}$ & $165(19.2 \%)$ & .725 \\
\hline $\begin{array}{l}\mathrm{CABG}+\mathrm{AV} \text { or } \mathrm{MV} \\
\quad \% \mathrm{CABG}+\mathrm{AV} / \mathrm{MV} \text { with } \mathrm{AKD} \S\end{array}$ & $\begin{array}{r}5(9.43 \%) \\
3.6 \%(5 / 137)\end{array}$ & $132(11.6 \%)$ & & $\begin{array}{l}7(16.3 \%) \\
5.1 \%(7 / 136)\end{array}$ & $129(15.0)$ & \\
\hline $\begin{array}{l}\text { Valve surgery } \\
\quad \% \text { Valve with } \mathrm{AKD} \|\end{array}$ & $\begin{array}{r}12(22.6 \%) \\
3.6 \%(12 / 335)\end{array}$ & $323(28.3 \%)$ & & $\begin{array}{r}14(32.6 \%) \\
5.7 \%(14 / 244)\end{array}$ & $230(26.8 \%)$ & \\
\hline $\begin{array}{l}\text { Heart Tx or VAD } \\
\% \text { Heart Tx/VAD with AKD }\end{array}$ & $\begin{array}{l}9(16.98 \%) \\
13 \%(9 / 96)\end{array}$ & $60(5.26 \%)$ & & $\begin{array}{l}3(6.98 \%) \\
2.9 \%(3 / 103)\end{array}$ & $100(11.7 \%)$ & \\
\hline $\begin{array}{l}\text { Other\# } \\
\quad \% \text { Other with } \mathrm{AKD}^{* *}\end{array}$ & $\begin{array}{r}16(30.2 \%) \\
4.3 \%(16 / 374)\end{array}$ & $358(31.4 \%)$ & & $\begin{array}{r}13(30.2 \%) \\
5.3 \%(13 / 247)\end{array}$ & $234(27.3)$ & \\
\hline \multicolumn{7}{|c|}{ Outcomes } \\
\hline Mortality & & & & & & \\
\hline $\begin{array}{l}\text { In hospital } \\
\text { 30-d }\end{array}$ & $\begin{array}{l}8(15.1 \%) \\
4(7.6 \%)\end{array}$ & $\begin{array}{l}20(1.75 \%) \\
17(1.49 \%)\end{array}$ & $\begin{array}{r}<.001 \\
.006\end{array}$ & $\begin{array}{r}19(44.2 \%) \\
9(20.9 \%)\end{array}$ & $\begin{array}{l}51(5.9 \%) \\
37(4.3 \%)\end{array}$ & $\begin{array}{l}<.001 \\
<.001\end{array}$ \\
\hline Need for RRT after surgery & $12(22.6 \%)$ & $9(0.79 \%)$ & $<.001$ & $22(51.2 \%)$ & $39(4.6 \%)$ & $<.001$ \\
\hline $\begin{array}{l}\text { KDIGO AKI stages } \\
\text { No AKI } \\
\text { Stage } 1 \\
\text { Stage } 2 \\
\text { Stage } 3\end{array}$ & $\begin{array}{r}17(32.1 \%) \\
6(11.3 \%) \\
11(20.8 \%) \\
19(35.9 \%)\end{array}$ & $\begin{array}{c}874(76.6 \%) \\
204(17.9 \%) \\
46(4.0 \%) \\
17(1.5 \%)\end{array}$ & $<.001$ & $\begin{aligned} 8 & (18.6 \%) \\
10 & (23.3 \%) \\
2 & (4.7 \%) \\
23 & (53.5 \%)\end{aligned}$ & $\begin{array}{c}594(69.2 \%) \\
189(22.0 \%) \\
24(2.8 \%) \\
51(5.9 \%)\end{array}$ & $<.001$ \\
\hline $\begin{array}{l}\text { Patients with AKI stages (1-3) } \\
\text { who developed AKD\# }\end{array}$ & $36(67.9 \%)$ & N/A & & $35(81.4 \%)$ & N/A & \\
\hline
\end{tabular}

$N K D$, No known kidney disease; $C K D$, chronic kidney disease; $A K D$, acute kidney disease; $S D$, standard deviation; $s C r$, serum creatinine; $e G F R$, estimated glomerular filtration rate; $C A B G$, coronary artery bypass grafting; $A V$, aortic valve; $M V$, mitral valve; $T x$, transplant; $V A D$, ventricular assist device; $R R T$, renal replacement therapy; $K D I G O$, Kidney Disease: Improving Global Outcomes; $A K I$, acute kidney injury; $N / A$, not applicable. *Denotes the AKD rate (\%) in patients who were male or female. †eGFR was calculated using the MDRD formula. ‡๋Denotes the AKD rate (\%) in patients who had a CABG only. §Denotes the AKD rate (\%) in patients who had a CABG+AV or MV. $\|$ Denotes the AKD rate $(\%)$ in patients who had valve surgery. 9 Denotes the AKD rate (\%) in patients who had heart transplant or VAD surgery. \#This was calculated by adding the patients who developed AKD with stages 1 to 3 AKI divided by all patients who developed AKD. **Denotes the AKD rate (\%) in patients who had other surgery (mainly congenital and surgery on the aorta).

We also found that patients who developed AKD had a higher risk of death and need for RRT. This finding can be valuable because it reaffirms the importance of following these patients closely, even after hospital discharge.

As noted in our study, our initial cohort consisted of 10,234 patients, but only $20.5 \%(\mathrm{n}=2095)$ of these patients had $\mathrm{sCr}$ values during this 2- to 4-week period. The most plausible explanation for why these patients were missing their $\mathrm{sCr}$ values after hospital discharge was that they had normal or stable kidney function at hospital discharge that did not warrant further clinical follow-up.
On the contrary, the patients who had their 2- to 4-week $\mathrm{sCr}$ values were likely patients who were at risk of kidney injury and had $\mathrm{sCr}$ values followed closely. In a separate analysis in which we used the last $\mathrm{sCr}$ value available as a surrogate for the missing 2- to 4-week sCr values, we found that the AKD rates, mortality, and need for RRT after surgery were lower in the cohort in whom we used surrogate values (total cohort) compared with those with $\mathrm{sCr}$ values during the 2- to 4-week postoperative period. This suggests the true incidence of AKD in patients with NKD and CKD is approximately between $1 \%$ and $4.4 \%$ and $2 \%$ and $4.8 \%$, respectively (Table E7). Of note, when we used the 
TABLE 3. Kidney Disease: Improving Global Outcomes acute kidney injury staging for patients with normal preoperative renal function and patients with preexisting chronic kidney disease predicts development of acute kidney disease (defined as doubling of serum creatinine by 2-4 wk after surgery)

\begin{tabular}{|c|c|c|c|c|c|c|c|c|c|}
\hline & \multicolumn{3}{|c|}{ Total cohort $(n=2095)$} & \multicolumn{3}{|c|}{$\operatorname{NKD}(n=1194)$} & \multicolumn{3}{|c|}{ Preexisting CKD $(n=901)$} \\
\hline & RR $[95 \% \mathbf{C I}]$ & $P$ value & $\mathbf{A U C}_{\mathbf{R O C}}{ }^{*}$ & RR $(95 \%$ CI $)$ & $P$ value & $\mathbf{A U C}_{\mathbf{R O C}}$ & RR $(95 \%$ CI) & $P$ value & $\mathbf{A U C}_{\mathbf{R O C}}$ \\
\hline No AKI & Ref & & $0.82(0.77-0.87)$ & Ref & & $0.84(0.78-0.90)$ & Ref & & $0.84(0.77-0.91)$ \\
\hline Stage 1 & $2.31[1.23-4.33]$ & .009 & & $1.36[0.53-3.47]$ & .522 & & $4.0[1.59-10.2]$ & .003 & \\
\hline Stage 2 & $9.36[4.74-18.5]$ & $<.001$ & & $9.57[4.42-20.7]$ & $<.001$ & & $6.0[1.25-29.1]$ & .003 & \\
\hline Stage 3 & $22.9[13.9-37.6]$ & $<.001$ & & $25.7[13.2-50.1]$ & $<.001$ & & $27.6[12.2-62.8]$ & .003 & \\
\hline
\end{tabular}

$N K D$, No known kidney disease; $C K D$, chronic kidney disease; $R R$, relative risk; $C I$, confidence interval; $A U C_{R O C}$, area under the receiver operating characteristic curve; $A K I$, acute kidney injury. *Adjusted for age, gender, and surgical type.
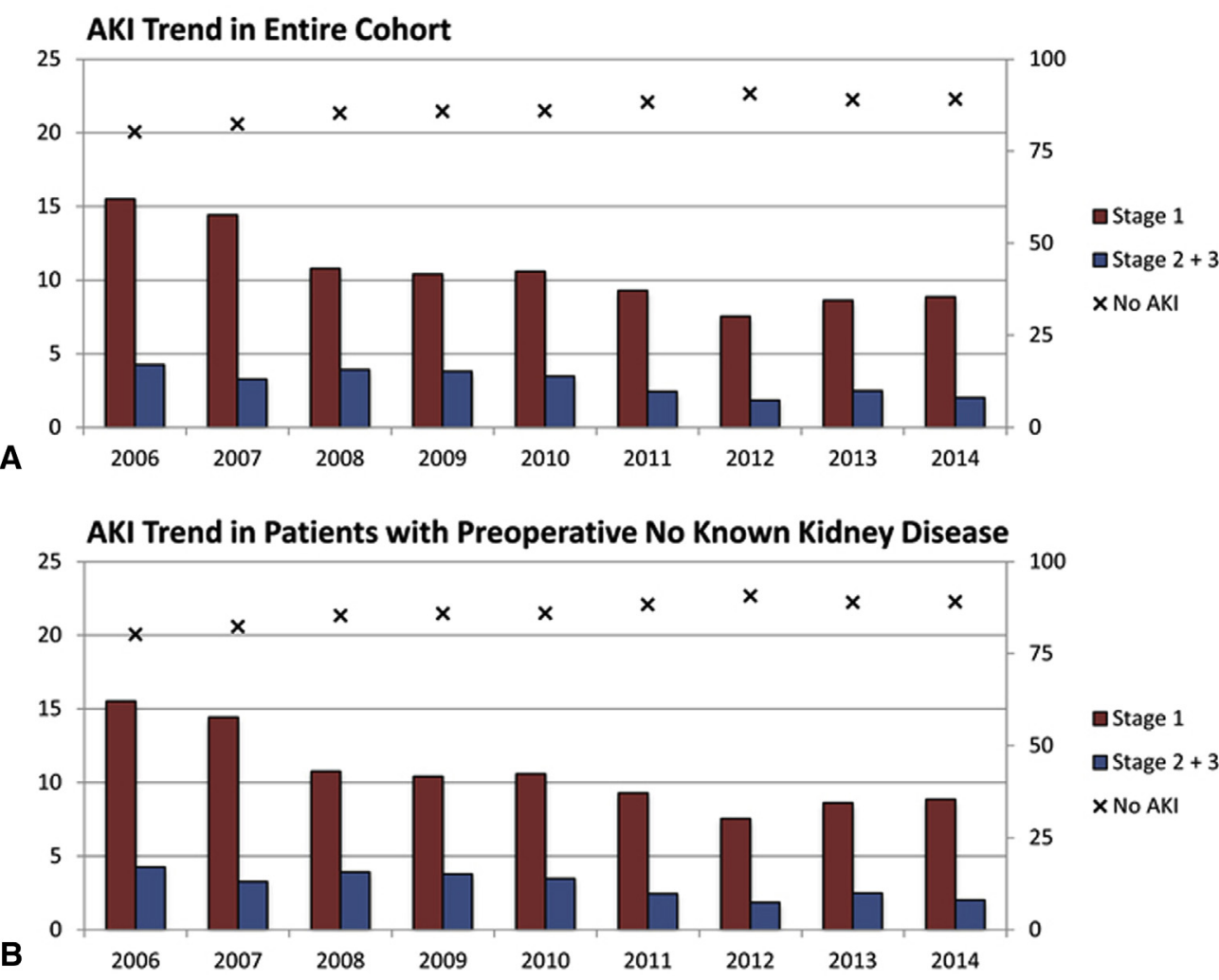

\section{0}

75

$\square$ Stage 1

$\square$ Stage $2+3$

$\times$ No AKI

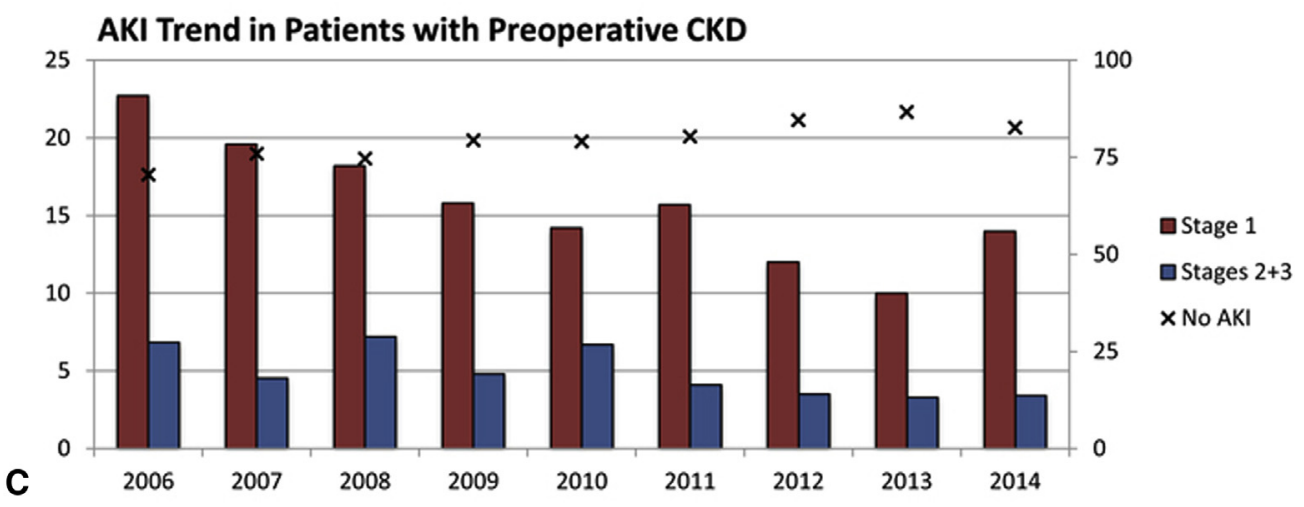

FIGURE 3. Trend of decreasing AKI over time (2006-2014) for patients undergoing cardiopulmonary bypass $(P<.001$ for trend of decreasing incidence of AKI). A, AKI trend in the entire cohort. B, AKI trend in patients with NKD. C, AKI trend in patients with preexisting CKD. The X-axis is represented by year: $\mathrm{y}$-axis on the left of the graph represents the percentage of patients with stage 1 or stage $2+3 \mathrm{AKI}$, and the $\mathrm{y}$-axis on the right of the graph represents the percentage of patients with no AKI. AKI, Acute kidney injury; $C K D$, chronic kidney disease. 
surrogate $\mathrm{sCr}$ values, we found that 41 additional patients (17 with NKD and 24 with CKD) would have been classified as developing AKD using this surrogate analysis (Table E7). Therefore, it is possible that these patients may have benefited from periodic $\mathrm{sCr}$ measurements even though they did not appear to be at risk.

Early identification of patients who progress to AKD is important, especially in cardiac surgery because these patients often return for other cardiac surgical or transcatheter procedures that may involve intravenous radiographic contrast administration or other hemodynamic insults that may increase their risk for developing subsequent, repeated AKI episodes. Therefore, we believe in the future, our prediction may be helpful in identifying patients who should be followed after discharge.

To predict the development of $\mathrm{AKD}$, we used $\mathrm{sCr}$ because we were interested in using a universally available biomarker rather than a novel biomarker because we believe identification of patients who develop progressive disease is important for patient care now. Although $\mathrm{sCr}$ is not an ideal biomarker for an acute process because it increases 24 to 72 hours after renal injury and $\mathrm{sCr}$ changes are not seen until $50 \%$ of renal function is lost, it is suitable for following CKD. ${ }^{9,10}$ By using novel biomarkers, it is possible that we could have identified more at-risk patients. ${ }^{11,12}$ We also chose to follow early changes in $\mathrm{sCr}$ (stages of KDIGO AKI) to predict the risk of progression to AKD because we believe this will allow development of large-scale collaborative studies targeted at this at-risk cohort.

We also evaluated the incidence of AKI over time and found that the overall incidence of AKI has steadily declined in both patients with NKD and CKD (Figure 3). Specifically, when we combined patients with AKI stages 2 and 3, and compared them with patients with AKI stage 1 , the incidence of AKI declined by approximately $50 \%$ from 2006 to 2014. This is interesting because the rate of AKI is increasing worldwide, and there is an initiative by the International Society of Nephrology to eliminate preventable deaths due to AKI by $2025 .{ }^{13}$ Although our study did not examine the possible causes of this improvement, it is noteworthy that our use of blood transfusions has significantly decreased during this period.

Our study has several strengths. First, we showed in a cohort of cardiac surgery patients that sCr-based AKI stages can predict the development of AKD after cardiopulmonary bypass for patients with no known preexisting kidney disease and with preoperative CKD. We also showed that patients with higher AKI stages were more likely to develop AKD in a graded manner. In patients with normal preoperative renal function and preexisting CKD, the ability of AKI stages to predict the development of AKD had a good predictive/diagnostic value with an $\mathrm{AUC}_{\mathrm{ROC}}=0.84($ Table 3$)$.

\section{Study Limitations}

As a retrospective observational study, we were unable to determine whether other important perioperative variables predict AKD. By classifying patients with normal glomerular filtration rate as patients with NKD, we assumed their normal eGFR reflected their true baseline. However, it is possible that patients classified as NKD may have been misclassified because they may have already had subacute AKI or AKD (not reflected by their creatinine value). It is also possible that a more sensitive biomarker would have helped determine whether these patients were accurately classified with normal kidney function at baseline.

Second, unadjusted crude estimates are presented except when we adjusted for 3 variables: age, gender, and surgery type. Future prospective studies designed to adjust for other confounders and variables such as blood transfusions and hemodynamic instability could both refine and validate our approach.

Third, many of our patients were missing their 2- to 4-week sCr data. We believe the majority of patients missing their 2- to 4-week sCr values were missing these values because clinically they had no indication to have $\mathrm{sCr}$ values checked after discharge because their $\mathrm{sCr}$ values returned to normal or to their baseline. Therefore, we studied only those patients with 2 - to 4 -week $\mathrm{sCr}$ values available. By doing this, our selection bias exaggerated the incidence of AKD, in-hospital and 30-day mortality, and need for RRT after surgery (Table E7).

\section{CONCLUSIONS}

Although the results are not generalizable to the entire cohort, we believe we found a meaningful method of identifying patients who may benefit from serial $\mathrm{sCr}$ measurements after discharge: patients who develop AKI stages 1 to 3 during their index admission. In addition, it is possible that an automated, real-time electronic alert system (as described by Porter and colleagues ${ }^{14}$ ) could send e-alerts to care providers when patients meet the AKI criteria. This could lead to increased awareness and recognition of those at risk for developing AKD and subsequent progression to CKD or end-stage renal disease. ${ }^{14}$

\section{Conflict of Interest Statement}

Authors have nothing to disclose with regard to commercial support.

The authors thank Sushrut S. Waikar, MD, for his valuable review of the manuscript and James Bell for his help with the graphics.

\section{References}

1. Zakkar M, Bruno VD, Guida G, Angelini GD, Chivasso P, Suleiman MS, et al. Postoperative acute kidney injury defined by RIFLE criteria predicts early health outcome and long-term survival in patients undergoing redo coronary artery bypass graft surgery. J Thorac Cardiovasc Surg. 2016;152:235-42. 
2. Hobson CE, Yavas S, Segal MS, Schold JD, Tribble CG, Layon AJ, et al. Acute kidney injury is associated with increased long-term mortality after cardiothoracic surgery. Circulation. 2009;119:2444-53.

3. Chawla LS, Eggers PW, Star RA, Kimmel PL. Acute kidney injury and chronic kidney disease as interconnected syndromes. N Engl J Med. 2014;371:58-66.

4. Chertow GM, Lazarus JM, Christiansen CL, Cook EF, Hammermeister KE, Grover F, et al. Preoperative renal risk stratification. Circulation. 1997;95:878-84.

5. Kidney Disease. Improving Global Outcomes (KDIGO) Acute Kidney Injury Work Group. KDIGO Clinical Practice Guideline for Acute Kidney Injury. Kidney Int. 2012;Suppl 2:1-138.

6. Levey AS, Coresh J, Greene T, Stevens LA, Zhang YL, Hendriksen S, et al. Using standardized serum creatinine values in the modification of diet in renal disease study equation for estimating glomerular filtration rate. Ann Intern Med. 2006; 145:247-54.

7. Mizuguchi KA, Mitani A, Waikar SS, Ireland P, Panizales C, Deluke G, et al. Use of postoperative creatinine to predict sustained kidney injury in patients undergoing mesothelioma surgery. Clin J Am Soc Nephrol. 2012;7:1071-8.

8. Zou GA. modified Poisson regression approach to prospective studies with binary data. Am J Epidemiol. 2004;159:702-6.

9. Chertow GM, Burdick E, Honour M, Bonventre JV, Bates DW. Acute kidney injury, mortality, length of stay, and costs in hospitalized patients. J Am Soc Nephrol. $2005 ; 16: 3365-70$.
10. Bagshaw SM, Gibney RT. Conventional markers of kidney function. Crit Care Med. 2008;36:S152-8.

11. Alge JL, Arthur JM. Biomarkers of AKI: a review of mechanistic relevance and potential therapeutic implications. Clin J Am Soc Nephrol. 2015;10: 147-55.

12. Belley-Cote EP, Parikh CR, Shortt CR, Coca SG, Garg AX, Eikelboom JW, et al Consortium T-A. Association of cardiac biomarkers with acute kidney injury af ter cardiac surgery: a multicenter cohort study. J Thorac Cardiovasc Surg. 2016; 152:245-51.e4.

13. Mehta RL, Cerda J, Burdmann EA, Tonelli M, Garcia-Garcia G, Jha V, et al. International Society of Nephrology's 0by25 initiative for acute kidney injury (zero preventable deaths by 2025): a human rights case for nephrology. Lancet. 2015; 385:2616-43.

14. Porter CJ, Juurlink I, Bisset LH, Bavakunji R, Mehta RL, Devonald MA. A realtime electronic alert to improve detection of acute kidney injury in a large teaching hospital. Nephrol Dial Transplant. 2014;29:1888-93.

Key Words: kidney disease progression, acute kidney injury, AKI, cardiac surgery, acute kidney disease, KDIGO AKI, predicting kidney disease progression, chronic kidney disease

Readers who found these articles interesting may also like to read the following papers found in recent and future issues of our sister publications, Seminars in Thoracic and Cardiovascular Surgery and Operative Techniques in Thoracic and Cardiovascular Surgery!

\section{Adult: Perioperative Management}

ORIGINAL SUBMISSION: Early Outcomes with Rapid-Deployment Versus Stented Biological Valves: a Propensity-Match Analysis. Anthony Nguyen. Semin Thoracic Surg 2017: In press.

Editorial Commentary: Rapid-Deployment Aortic Valve Replacement: Clear Benefits Without a Clear Target Patient Population. Craig M. Jarrett. Semin Thoracic Surg 2017: In press.

ORIGINAL SUBMISSION: Randomized Trial of Carnitine for the Prevention of Perioperative Atrial Fibrillation. Farzaneh Dastan. Semin Thoracic Surg 2017: In press.

Editorial Commentary: Preventing Postoperative Atrial Fibrillation: is There One Best Option? Vincent R. Conti. Semin Thoracic Surg 2017: In press.

ORIGINAL SUBMISSION: Carbon Dioxide Insufflation during Cardiac Surgery. Meta-Analysis of Randomized Controlled Trials. Umberto Benedetto. Semin Thoracic Surg 2017: 301-310. 
TABLE E1. Definitions of stages of kidney disease progression ${ }^{5}$

\begin{tabular}{ll}
\hline Definition & \multicolumn{1}{c}{ Criteria } \\
\hline NKD & GFR $\geq 60 \mathrm{~mL} / \mathrm{min} / 1.73 \mathrm{~m}^{2}$ \\
AKI & sCr increase by $50 \%$ within $7 \mathrm{~d}$ or $0.3 \mathrm{mg} / \mathrm{dL}$ within $2 \mathrm{~d}$ or oliguria \\
& Stage $1: \mathrm{sCr}$ increase $1.5-1.9$ times baseline or $\geq 0.3 \mathrm{mg} / \mathrm{dL}$ increase; urine output $<0.5 \mathrm{~mL} / \mathrm{kg} / \mathrm{h} \mathrm{for} 6-12 \mathrm{~h}$ \\
& Stage $2: \mathrm{sCr}$ increase $2-2.9$ times baseline; urine output $<0.5 \mathrm{~mL} / \mathrm{kg} / \mathrm{h}$ for $\geq 12 \mathrm{~h}$ \\
& Stage $3: \mathrm{sCr}$ increase 3 times baseline or increase in $\mathrm{sCr} \geq 4 \mathrm{mg} / \mathrm{dL}$ or initiation of $\mathrm{RRT}$ or in patients $<18 \mathrm{y}$, \\
& decrease in eGFR $<35 \mathrm{~mL} / \mathrm{min} / 1.73 \mathrm{~m}^{2} ;$ anuria $\geq 12 \mathrm{~h}$ \\
AKD & AKI or \\
& GFR $<60 \mathrm{~mL} / \mathrm{min} / 1.73 \mathrm{~m}^{2}<3 \mathrm{mo}$ or \\
& Decrease in GFR $35 \%$ or increase in sCr $>50 \%<3 \mathrm{mo}$ \\
& Structural kidney damage $<3 \mathrm{mo}$ \\
CKD & GFR $<60 \mathrm{~mL} / \mathrm{min} / 1.73 \mathrm{~m}^{2}>3 \mathrm{mo}$ \\
& Structural kidney damage $>3 \mathrm{mo}$
\end{tabular}

$N K D$, No known kidney disease; $G F R$, glomerular filtration rate; $A K I$, acute kidney injury; $s C r$, serum creatinine; $R R T$, renal replacement therapy; $e G F R$, estimated glomerular filtration rate; $A K D$, acute kidney disease; $C K D$, chronic kidney injury. 
TABLE E2. Development of acute kidney disease (defined by doubling of serum creatinine or by decrease in estimated glomerular filtration rate $\geq \mathbf{3 5} \%)$ in patients with no known prior kidney disease $(\mathbf{n}=\mathbf{2 0 9 5})$

\begin{tabular}{|c|c|c|c|c|c|c|}
\hline \multicolumn{7}{|c|}{ Patient characteristics } \\
\hline \multirow[b]{2}{*}{ Definition of AKD } & \multicolumn{3}{|c|}{ Doubling of sCr } & \multicolumn{3}{|c|}{ Decrease in eGFR $\geq \mathbf{3 5} \%$} \\
\hline & $\overline{A K D}(\mathbf{n}=\mathbf{5 3})$ & No AKD $(n=1141)$ & $P$ value & $\operatorname{AKD}(\mathbf{n}=237)$ & No AKD $(n=957)$ & $P$ value \\
\hline Age (y), mean (SD) & $64(17.5)$ & $64(14.8)$ & .83 & $67(14.1)$ & $63(15.0)$ & $<.001$ \\
\hline $\begin{array}{l}\text { Gender (male) } \\
\% \text { male with } \mathrm{AKD}^{*} \\
\% \text { female with } \mathrm{AKD}^{*}\end{array}$ & $\begin{array}{r}38(71.1 \%) \\
4.9 \%(38 / 782) \\
3.6 \%(15 / 412)\end{array}$ & $744(65.2 \%)$ & .41 & $\begin{array}{c}160(67.5 \%) \\
20.5 \%(160 / 782) \\
36 \%(77 / 412)\end{array}$ & $622(65.0 \%)$ & .514 \\
\hline Preoperative sCr, mean (SD) & $0.86(0.18)$ & $0.88(0.16)$ & .56 & $0.85(0.17)$ & $0.88(0.16)$ & .022 \\
\hline Preoperative eGFR, mean (SD) $\dagger$ & $96.1(35.5)$ & $89.6(28.4)$ & .2 & $94.2(31.6)$ & $88.8(28.0)$ & .017 \\
\hline \multicolumn{7}{|c|}{ Type of surgery } \\
\hline CABG only & $11(20.75 \%)$ & $268(23.5 \%)$ & .011 & $73(30.8 \%)$ & $206(21.53 \%)$ & .011 \\
\hline$\% \mathrm{AKD}$ in $\mathrm{CABG}$ only & $3.9 \%(11 / 279)$ & & & $26.2 \%(73 / 279)$ & & \\
\hline $\mathrm{CABG}+\mathrm{AV}$ or $\mathrm{MV}$ & $5(9.43 \%)$ & $132(11.6 \%)$ & & $27(11.39 \%)$ & $110(11.49 \%)$ & \\
\hline$\% \mathrm{AKD}$ in $\mathrm{CABG}+\mathrm{AV} / \mathrm{MV} \S$ & $3.6 \%(5 / 137)$ & & & $19.7(27 / 137)$ & & \\
\hline Valve surgery & $12(22.6 \%)$ & $323(28.3 \%)$ & & $51(21.52 \%)$ & $284(29.68 \%)$ & \\
\hline$\% \mathrm{AKD}$ in valve $\|$ & $3.6 \%(12 / 335)$ & & & $15.2 \%(51 / 335)$ & & \\
\hline Heart Tx or VAD & $9(16.98 \%)$ & $60(5.26 \%)$ & & $17(7.17 \%)$ & $52(5.43 \%)$ & \\
\hline$\% \mathrm{AKD}$ in $\mathrm{Tx}$ or $\mathrm{VAD}$ & $13 \%(9 / 69)$ & & & $24.6 \%(17 / 69)$ & & \\
\hline Other & $16(30.2 \%)$ & $358(31.4 \%)$ & & $69(29.11 \%)$ & $305(31.87 \%)$ & \\
\hline$\%$ AKD in other\# & $4.3 \%(16 / 374)$ & & & $18.4 \%(69 / 374)$ & & \\
\hline \multicolumn{7}{|c|}{ Outcomes } \\
\hline Mortality & & & & & & \\
\hline In hospital & $8(15.1 \%)$ & $20(1.75 \%)$ & $<.001$ & $22(9.28 \%)$ & $6(0.63 \%)$ & $<.001$ \\
\hline $30-d$ & $4(7.6 \%)$ & $17(1.49 \%)$ & .006 & $12(5.06 \%)$ & $9(0.94 \%)$ & $<.001$ \\
\hline Need for RRT after surgery & $12(22.6 \%)$ & $9(0.79 \%)$ & $<.001$ & $17(7.17 \%)$ & $4(0.42 \%)$ & $<.001$ \\
\hline KDIGO AKI Stages & & & $<.001$ & & & $<.001$ \\
\hline No AKI & $17(32.1 \%)$ & $874(76.6 \%)$ & & $104(43.88 \%)$ & $787(82.24 \%)$ & \\
\hline Stage 1 & $6(11.3 \%)$ & $204(17.9 \%)$ & & $77(32.49 \%)$ & $133(13.9 \%)$ & \\
\hline Stage 2 & $11(20.8 \%)$ & $46(4.0 \%)$ & & $28(11.81 \%)$ & $29(3.03 \%)$ & \\
\hline Stage 3 & $19(35.9 \%)$ & $17(1.5 \%)$ & & $28(11.81 \%)$ & $8(0.84 \%)$ & \\
\hline $\begin{array}{l}\text { Patients with AKI stages (1-3) } \\
\text { who developed AKD }\end{array}$ & $36(67.9 \%)^{* *}$ & N/A & & $133(56.1 \%)^{* * *}$ & N/A & \\
\hline
\end{tabular}

$A K D$, Acute kidney disease; $S C r$, serum creatinine; $e G F R$, estimated glomerular filtration rate; $S D$, standard deviation; $C A B G$, coronary artery bypass grafting; $A V$, aortic valve; $M V$, mitral valve; $T x$, transplant; $V A D$, ventricular assist device; $R R T$, renal replacement therapy; $K D I G O$, Kidney Disease: Improving Global Outcomes; $A K I$, acute kidney injury; N/A, not applicable. *Denotes the AKD rate (\%) in patients who were male or female. †eGFR was calculated using the MDRD formula. $\ddagger$ Denotes the AKD rate $(\%)$ in patients who had a CABG only. §Denotes the AKD rate (\%) in patients who had a CABG+AV or MV. ||Denotes the AKD rate (\%) in patients who had valve surgery. 9 Denotes the AKD rate $(\%)$ in patients who had heart transplant or VAD surgery. \#Denotes the AKD rate $(\%)$ in patients who had other surgery (mainly congenital and surgery on the aorta). **This was calculated by adding the patients who developed AKD with stages 1 to 3 AKI divided by all patients who developed AKD. 
TABLE E3. Development of acute kidney disease (defined by doubling of serum creatinine or by decrease in estimated glomerular filtration rate $\geq \mathbf{3 5} \%)$ in patients with preexisting chronic kidney disease $(\mathbf{n}=\mathbf{9 0 1})$

\begin{tabular}{|c|c|c|c|c|c|c|}
\hline \multicolumn{7}{|c|}{ Patient characteristics } \\
\hline \multirow[b]{2}{*}{ Definition of AKD } & \multicolumn{3}{|c|}{ Doubling of sCr } & \multicolumn{3}{|c|}{ Decrease in eGFR $\geq \mathbf{3 5} \%$} \\
\hline & $\overline{\mathrm{AKD}}(\mathrm{n}=\mathbf{4 3})$ & No AKD $(n=858)$ & $P$ value & $\overline{\mathrm{AKD}(\mathrm{n}=174)}$ & No AKD $(n=727)$ & $\overline{P \text { value }}$ \\
\hline Age $(y)$, mean $(\mathrm{SD})$ & $73(12.2)$ & $71(12.3)$ & .459 & $72.21(12.15)$ & $70.39(12.32)$ & .078 \\
\hline $\begin{array}{l}\text { Gender (male) } \\
\% \text { male with } \mathrm{AKD}^{*} \\
\% \text { female with } \mathrm{AKD}^{*}\end{array}$ & $\begin{array}{r}24(55.8 \%) \\
(24 / 534) \\
(19 / 367)\end{array}$ & $510(59.4 \%)$ & .754 & $\begin{array}{c}100(57.47 \%) \\
(100 / 534) \\
(74 / 367)\end{array}$ & $434(59.7 \%)$ & .652 \\
\hline Preoperative sCr & $1.4(0.39)$ & $1.48(0.58)$ & .247 & $1.46(0.48)$ & $1.49(0.59)$ & .455 \\
\hline Preoperative eGFR $\dagger$ & $42.6(11.52)$ & $41.1(12.73)$ & .415 & $41.06(12.05)$ & $41.25(12.82)$ & .854 \\
\hline \multicolumn{7}{|c|}{ Type of surgery } \\
\hline CABG only & $6(13.95 \%)$ & $165(19.23 \%)$ & .725 & $33(18.97 \%)$ & $138(18.98 \%)$ & .197 \\
\hline$\% \mathrm{AKD}$ in $\mathrm{CABG}$ only & $3.5 \%(6 / 171)$ & & & $19.3 \%(33 / 171)$ & & \\
\hline $\mathrm{CABG}+\mathrm{AV}$ or $\mathrm{MV}$ & $7(16.28 \%)$ & $129(15.03 \%)$ & & $33(18.97 \%)$ & $103(14.17 \%)$ & \\
\hline$\% \mathrm{AKD}$ in $\mathrm{CABG}+\mathrm{AV} / \mathrm{MV} \S$ & $5.1 \%(7 / 136)$ & & & $24.3 \%(33 / 136)$ & & \\
\hline Valve surgery & $14(32.56 \%)$ & $230(26.81 \%)$ & & $43(24.71 \%)$ & $201(27.65 \%)$ & \\
\hline$\% \mathrm{AKD}$ in valve $\|$ & $5.7 \%(14 / 244)$ & & & $17.6 \%(43 / 244)$ & & \\
\hline Heart Tx or VAD & $3(6.98 \%)$ & $100(11.66 \%)$ & & $13(7.47 \%)$ & $90(12.38 \%)$ & \\
\hline$\% \mathrm{AKD}$ in $\mathrm{Tx}$ or $\mathrm{VAD}$ & $2.9 \%(3 / 103)$ & & & $12.6 \%(13 / 103)$ & & \\
\hline Other* & $13(30.2 \%)$ & $234(27.3 \%)$ & & $52(29.89 \%)$ & $195(26.82 \%)$ & \\
\hline$\% \mathrm{AKD}$ in other\# & $5.3 \%(13 / 247)$ & & & $21 \%(52 / 247)$ & & \\
\hline \multicolumn{7}{|l|}{ Mortality } \\
\hline In hospital & $19(44.2 \%)$ & $51(5.9 \%)$ & $<.001$ & $45(25.86 \%)$ & $25(3.44 \%)$ & $<.001$ \\
\hline $30-d$ & $9(20.9 \%)$ & $37(4.3 \%)$ & $<.001$ & $27(15.52 \%)$ & $19(2.61 \%)$ & $<.001$ \\
\hline Need for RRT after surgery & $22(51.2 \%)$ & $39(4.6 \%)$ & $<.001$ & $42(24.14 \%)$ & $19(2.61 \%)$ & $<.001$ \\
\hline KDIGO AKI stages & & & $<.001$ & & & .197 \\
\hline No AKI & $8(18.6 \%)$ & $594(69.2 \%)$ & & $33(18.97 \%)$ & $138(18.98 \%)$ & \\
\hline Stage 1 & $10(23.3 \%)$ & $189(22.0 \%)$ & & $33(18.97 \%)$ & $103(14.17 \%)$ & \\
\hline Stage 2 & $2(4.7 \%)$ & $24(2.8 \%)$ & & $43(24.71 \%)$ & $201(27.65 \%)$ & \\
\hline Stage 3 & $23(53.5 \%)$ & $51(5.9 \%)$ & & $13(7.47 \%)$ & $90(12.38 \%)$ & \\
\hline $\begin{array}{c}\text { Patients with AKI stages (1-3) } \\
\text { who developed AKD*** }\end{array}$ & $35(81.4 \%)$ & N/A & & $89(51.1 \%)$ & N/A & \\
\hline
\end{tabular}

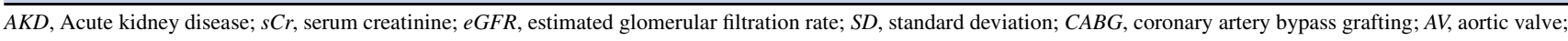
$M V$, mitral valve; $T x$, transplant; $V A D$, ventricular assist device; $R R T$, renal replacement therapy; $K D I G O$, Kidney Disease: Improving Global Outcomes; $A K I$, acute kidney injury; $N / A$, not applicable. *Denotes the AKD rate (\%) in patients who were male or female. †eGFR was calculated using the MDRD formula. ‡Denotes the AKD rate (\%) in patients who had CABG only. §Denotes the AKD rate (\%) in patients who had CABG+AV or MV. |Denotes the AKD rate (\%) in patients who had valve surgery. 9 Denotes the AKD rate (\%) in patients who had heart transplant or VAD surgery. \#Denotes the AKD rate (\%) in patients who had other surgery (mainly congenital and surgery on the aorta). **This was calculated by adding the patients who developed AKD with stages 1 to 3 AKI divided by all patients who developed AKD 
TABLE E4. Ability of Kidney Disease: Improving Global Outcomes acute kidney injury stages to predict the development of acute kidney disease (defined as decrease estimated glomerular filtration rate $\geq 35 \%$ present $2-4 \mathrm{wk}$ after surgery) for both patients with normal preoperative renal function or with preexisting chronic kidney disease

\begin{tabular}{|c|c|c|c|c|c|c|c|c|c|}
\hline & \multicolumn{3}{|c|}{ Total cohort $(n=2095)$} & \multicolumn{3}{|c|}{$\operatorname{NKD}(n=1194)$} & \multicolumn{3}{|c|}{ Preexisting CKD $(n=901)$} \\
\hline & $\overline{R R ~[95 \% ~ C I] ~}$ & $P$ value & AUC $_{\text {ROC }}{ }^{*}$ & OR $(95 \%$ CI $)$ & $P$ value & $\mathbf{A U C}_{\mathbf{R O C}}$ & OR $(95 \%$ CI $)$ & $P$ value & $\mathbf{A U C}_{\mathrm{ROC}}$ \\
\hline No AKI & Ref & & $0.754(0.73-0.78)$ & Ref & & $0.764(0.73-0.798)$ & Ref & & $0.759(0.72-0.8)$ \\
\hline Stage 1 & $2.73[2.2-3.5]$ & $<.001$ & & $3.16[2.35-4.25]$ & $<.001$ & & $2.28[1.57-3.32]$ & $<.003$ & \\
\hline Stage 2 & $4.4[3.1-6.2]$ & $<.001$ & & $4.36[2.86-6.66]$ & $<.001$ & & $4.21[2.25-7.89]$ & $<.003$ & \\
\hline Stage 3 & $6.49[4.95-8.5]$ & $<.001$ & & $6.91[4.53-10.53]$ & $<.001$ & & $6.74[4.62-9.83]$ & $<.003$ & \\
\hline
\end{tabular}

$N K D$, No known kidney disease; $C K D$, chronic kidney disease; $R R$, relative risk; $C I$, confidence interval; $A U C_{R O C}$, area under the receiver operating characteristic curve; $O R$, odds ratio; $A K I$, acute kidney injury. *Adjusted for age, gender, and surgical type.

TABLE E5. Comparison of patients with 2- to 4-week serum creatinine data available with those without

\begin{tabular}{|c|c|c|c|}
\hline & $\begin{array}{l}\text { 2- to 4-wk data available } \\
\qquad(\mathrm{n}=2095) \\
\end{array}$ & $\begin{array}{l}\text { Missing 2- to 4-wk data } \\
\quad(n=8139)\end{array}$ & $P$ value \\
\hline \multicolumn{4}{|l|}{ Preoperative characteristics } \\
\hline $\operatorname{Age}(y)$, mean $(S D)$ & $66.97(14.23)$ & $66.77(13.27)$ & .576 \\
\hline Gender (male), n (\%) & $1316(62.82 \%)$ & $5417(66.56 \%)$ & $<.001$ \\
\hline Preoperative sCr, mean (SD) & $1.14(0.49)$ & $1.02(0.33)$ & $<.001$ \\
\hline Preoperative eGFR, mean (SD)* & $68.92(33.49)$ & $75.65(29.06)$ & $<.001$ \\
\hline Preexisting CKD & $901(43.01 \%)$ & $2381(29.25 \%)$ & $<.001$ \\
\hline Type of surgery & & & $<.001$ \\
\hline CABG only & $450(21.48 \%)$ & $2719(33.41 \%)$ & \\
\hline $\mathrm{CABG}+\mathrm{AV}$ or $\mathrm{MV}$ & $273(13.03 \%)$ & $1004(12.34 \%)$ & \\
\hline Valve surgery & $579(27.64 \%)$ & $2500(30.72 \%)$ & \\
\hline Heart Tx or VAD & $172(8.21 \%)$ & $10(0.12 \%)$ & \\
\hline Other ${ }^{\dagger}$ & $621(29.64 \%)$ & $1906(23.42 \%)$ & \\
\hline \multicolumn{4}{|l|}{ Outcomes } \\
\hline In-hospital mortality & $98(4.68 \%)$ & $96(1.18 \%)$ & $<.001$ \\
\hline 30-d mortality, $\%$ & $67(3.2 \%)$ & $112(1.38 \%)$ & $<.001$ \\
\hline Need for RRT after surgery, $\%$ & $82(3.91 \%)$ & $37(0.45 \%)$ & $<.001$ \\
\hline \multicolumn{4}{|l|}{ Incidence of KDIGO AKI stages } \\
\hline No AKI & $1493(71.26 \%)$ & $7306(89.77 \%)$ & $<.001$ \\
\hline Stage 1 & $409(19.52 \%)$ & $704(8.65 \%)$ & \\
\hline Stage 2 & $83(3.96 \%)$ & $63(0.77 \%)$ & \\
\hline Stage 3 & $110(5.25 \%)$ & $66(0.81 \%)$ & \\
\hline
\end{tabular}

$S D$, Standard deviation; $s C r$, serum creatinine; $e G F R$, estimated glomerular filtration rate; $C K D$, chronic kidney injury; $C A B G$, coronary artery bypass grafting; $A V$, aortic valve; $M V$, mitral valve; $T x$, transplant; $V A D$, ventricular assist device; $R R T$, renal replacement therapy; $K D I G O$, Kidney Disease: Improving Global Outcomes; $A K I$, acute kidney injury. *eGFR was calculated using the MDRD formula. †Other mainly included congenital and surgery on the aorta. 
TABLE E6. Comparison of acute kidney injury rates

\begin{tabular}{|c|c|c|}
\hline Cohort & AKI (stages 1-3) & No AKI \\
\hline \multicolumn{3}{|l|}{ Total cohort* } \\
\hline Total cohort $(\mathrm{n}=10,234)$ & $1435(14 \%)$ & $8799(86 \%)$ \\
\hline No prior kidney disease $(n=6952)$ & $736(10.6 \%)$ & $6216(89.4 \%)$ \\
\hline Preoperative CKD $(\mathrm{n}=3282)$ & $699(21.3 \%)$ & $2583(78.7 \%)$ \\
\hline \multicolumn{3}{|l|}{$\begin{array}{l}\text { Cohort with } 2-4 \mathrm{wk} \text { postoperative } \mathrm{sCr} \\
\text { available }\end{array}$} \\
\hline 2-4 wk sCr available $(\mathrm{n}=2095)$ & $602(28.7 \%)$ & $1493(71.3 \%)$ \\
\hline No prior kidney disease $(\mathrm{n}=1195)$ & $303(25.4 \%)$ & $891(74.6 \%)$ \\
\hline Preoperative CKD $(\mathrm{n}=901)$ & $299(33.2 \%)$ & $602(66.8 \%)$ \\
\hline
\end{tabular}

TABLE E7. Comparison of outcomes between cohort with 2- to 4-week postoperative serum creatinine available $(\mathrm{n}=\mathbf{2 0 9 5 )}$ versus total cohort $(\mathbf{n}=\mathbf{1 0 , 2 3 4})$

\begin{tabular}{|c|c|c|c|}
\hline \multicolumn{4}{|c|}{ Outcomes* } \\
\hline \multicolumn{4}{|c|}{ Incidence of AKD } \\
\hline Cohort & NKD & Preexisting CKD & $P$ value \\
\hline Cohort with 2-4 wk postoperative sCr available $\dagger$ & $53(4.4 \%)$ & $43(4.8 \%)$ & .798 \\
\hline Total cohort $\ddagger$ & $70(1 \%)$ & $67(2.0 \%)$ & $<.001$ \\
\hline \multicolumn{4}{|c|}{ Other outcomes } \\
\hline \multicolumn{4}{|l|}{ Cohort with 2-4 wk postoperative sCr available } \\
\hline In-hospital mortality & $28(2.35 \%)$ & $70(7.77 \%)$ & $<.001$ \\
\hline 30-d mortality, \% & $21(1.76 \%)$ & $46(5.11 \%)$ & $<.001$ \\
\hline Need for RRT after surgery, $\%$ & $21(1.76 \%)$ & $61(6.77 \%)$ & $<.001$ \\
\hline \multicolumn{4}{|l|}{ Total cohort } \\
\hline In-hospital mortality & $65(0.93 \%)$ & $129(3.93 \%)$ & $<.001$ \\
\hline 30-d mortality, $\%$ & $63(0.9 \%)$ & $116(3.5 \%)$ & $<.001$ \\
\hline Need for RRT after surgery, $\%$ & $34(0.5 \%)$ & $85(2.6 \%)$ & $<.001$ \\
\hline \multicolumn{4}{|c|}{ 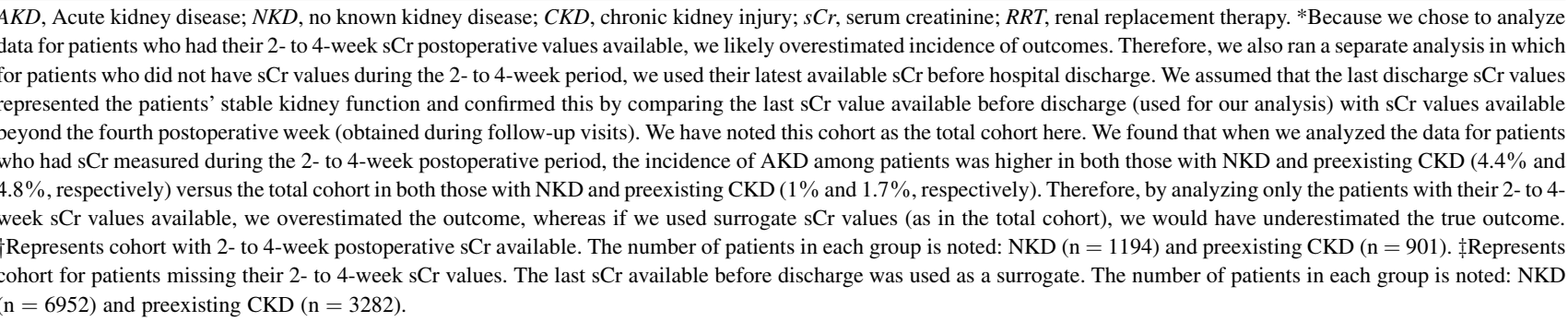 } \\
\hline
\end{tabular}

